\title{
Bioeconomics of foraging route selection by limpets
}

\author{
Giacomo Santini $^{1, *}{ }^{\text {, Michael T. Burrows }}{ }^{2}$, Guido Chelazzi ${ }^{1}$ \\ ${ }^{1}$ Dipartimento di Biologia Animale e Genetica, Università degli Studi di Firenze, Via Romana 17, 50125 Florence, Italy \\ ${ }^{2}$ Scottish Association for Marine Science, Dunstaffnage Marine Laboratory, Oban, Argyll PA37 1QA, UK
}

\begin{abstract}
Homing limpets are central place foragers whose activity is constrained to restricted diel and tidal phases. The limpets' slow motion and high energy requirements render the problem of early choice of suitable foraging sites a critical issue. Mucous trails could be used, however, to relocate previously visited foraging areas. In this paper we describe a simulation model comparing 3 possible patch-choice tactics. These are random choice (RC) and 2 strategies (MVK and MVU) based on a marginal-value rule. The MVK strategy assumes that the forager is able to perceive and keep track of changes in energy return from successive visits to the same patch, while the MVU does not. The average long-term energy gain provided by the 3 strategies was calculated under a set of external factors: variability in the distance of patches from the central place, average value and variability in standing crop and predictability of rewards from the same foraging site when visited over successive times (autocorrelation). In the absence of variability in food sources, the different tactics yielded comparable energy returns, irrespective of average standing crop level, distance from home and autocorrelation in rewards. As variability in food sources increased, the final energy gain provided by MVK and MVU strategies changed according to the degree of autocorrelation. The MVK strategy performed increasingly better than RC for increasing autocorrelation values. The MVU strategy performed better than RC when energy returns from successive visits were positively correlated. On the contrary, in the case of a negative correlation the RC strategy was better than the MVU one.
\end{abstract}

KEY WORDS: Intertidal molluscs $\cdot$ Limpets $\cdot$ Optimal foraging $\cdot$ Central place

\section{INTRODUCTION}

Since natural food distribution may vary considerably both in time and space, efficient foragers would be expected to learn the position and quality of food sources, and visit them according to perceived rates of potential energy gains. This ability may be particularly relevant for central place foragers since adopting a temporally stable home site may allow the animal to gain better and more reliable information about the energy content and spatial location of nearby food patches (Stephens \& Krebs 1986, Bell 1991).

Classical central place foraging models address the problem of optimising acceptance thresholds for food items or patches, when encountered by a forager at various distances from the refuge (Stephens \& Krebs
1986). Much of the analytical effort has been focused on the behaviour within each foraging excursion, and only limited attempts have been made to model the behaviour over subsequent activity bouts (e.g. Armstrong et al. 1987).

Intertidal homing molluscs, and particularly limpets, are good subjects for studying feeding patterns in central place foragers. Scar fidelity, a limited behavioural repertoire and a restricted foraging ambit make them very suitable for long term temporal and spatial monitoring of behaviour (Chelazzi et al. 1990). Moreover, many of these species are able to relocate particular spatial locations through following previously laid mucous trails, whose homeward and outward (i.e. foodward) branches may have a different information content (e.g. McFarlane 1981, Chelazzi et al. 1987, 
Davies \& Hawkins 1998). Other features also make homing molluscs particularly interesting for assessing the bioeconomics of behaviour in central place foraging: intertidal molluscs are slow-moving animals whose activity is strongly constrained by both physical (see dehydration, heat stress) and biotic (predation) factors to narrow, suitable tidal/diel phases (e.g. Hawkins \& Hartnoll 1983, Little 1989, Chapman \& Underwood 1992 for reviews). In addition, the cost per unit time of motion is higher than in other animals, due to mucus secretion (e.g. Denny 1980, Davies \& Hawkins 1998). This set of constraints makes the problem of the early a priori choice of a suitable foraging site particularly relevant, since visiting an unsuitable patch may entail a considerable waste of energy, a significant cost of lost opportunities and additional mortality risks. Accordingly, evidence exists for some species that, although en route calibration of foraging trajectory is possible, much of the spatial organisation of foraging relies on earlier decisions taken when leaving the home scar (e.g. Chelazzi et al. 1998).

Field records of the behaviour of molluscs have shown that different species are likely to adopt different patch revisiting strategies. Evidence of sequential non-random revisiting of a previously exploited foraging patch has been obtained for the gastropods Onchidium sp. (McFarlane 1980) and Patella vulgata (Chelazzi et al. 1998), and the chiton Acanthopleura gemmata (Chelazzi et al. 1987). In contrast, a study conducted on the Mediterranean high shore limpet $P$. rustica (Chelazzi et al. 1994) revealed a cropping pattern based on random angular selection, weakly biased towards avoidance of the last foraging excursion. Avoidance of the last patch visited has also been described for the 2 pulmonate limpets Siphonaria normalis and S. alternata (Cook \& Cook 1981). Despite attempts to interpret the observed patterns in relation to known features of the environment and the biology of the species, no studies have examined the costs and benefits of observed behaviours.

The aim of the present study was to propose a simple foraging model to determine whether experience-based decision rules for returning to lastvisited areas would give an improved rate of long-term energetic return, when compared to a simple random choice tactic. The model was formulated to represent limpet behaviour but the results have potential for wider application.

\section{MATERIALS AND METHODS}

The model. The foraging area of limpets is considered as a series of non-overlapping sectors (Fig. 1a). At the beginning of a foraging period, a limpet chooses one of these sectors and travels out to the unexploited part located at its distal edge, where it begins to feed without straying out of the sector (Fig. 1b). Only 1 sector is assumed to be visited during an activity phase. This schematic representation of foraging activity, although simplistic, seems appropriate given the foraging path geometry of Patella spp. (e.g. Hartnoll \& Wright 1977, Della Santina et al. 1995). During foraging, limpets are assumed to remove all the food encountered and, for simplicity, the microbial film is not replenished after grazing.

The total time available for activity is fixed and bounded to an upper value, $T$. Limpets are usually time-constrained foragers and restrict their activity to particular combinations of the tidal (ebb and flood) and diel (day/night) cycles. Total time $T$ can be partitioned into 2 separate components:

$$
T=T_{\mathrm{V}}+T_{\mathrm{F}}
$$

where $T_{\mathrm{V}}$, is the time spent travelling to and from the feeding area and $T_{\mathrm{F}}$ is the time devoted to foraging. Given that a limpet moves up to a distance $D$ at a

(a)
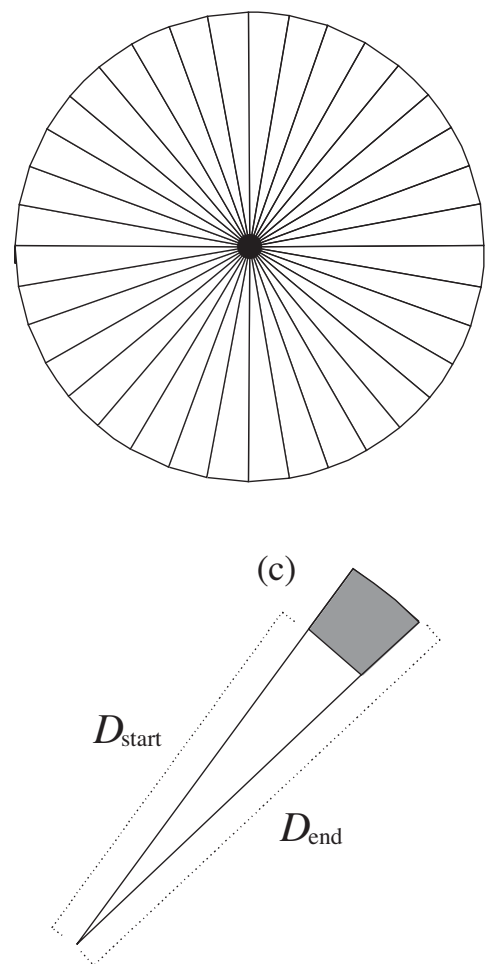

(b)

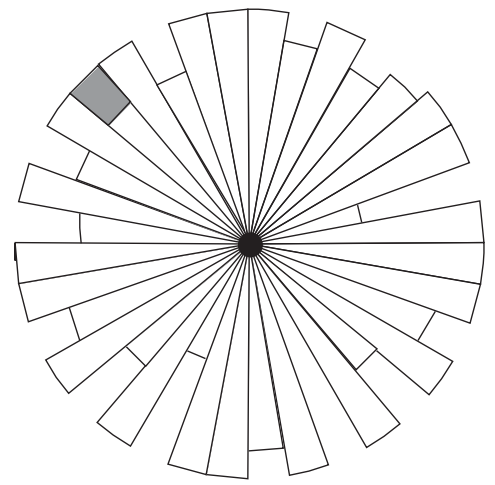

Fig. 1. Schematic representation of a limpet Patella spp. foraging area. (a) Initial condition; (b) after several foraging excursions have been performed; (c) details of a foraging sector; $D_{\text {start }}$ and $D_{\text {end }}$ represent the distance from the home to the sector's edge, at the beginning and the end of a foraging excursion, respectively. Shaded area in (b) and (c) shows the area removed during a single foraging bout 
speed $V$, and must return to its home scar before the end of the foraging period, $T_{\mathrm{V}}$ will be:

$$
\begin{array}{cc}
T_{\mathrm{V}} & =2 \mathrm{D} / \mathrm{V} \\
\text { and hence: } & T_{\mathrm{F}}=T-2 \mathrm{D} / \mathrm{V}
\end{array}
$$

The total energy returned from a foraging bout $G_{\text {total }}$ is the energy gained from foraging less the total energetic costs of foraging, $T C$ :

$$
G_{\text {total }}=(T-2 D / V) \times E-T C
$$

Here $E$ is the rate of energy extraction while foraging $\left(\mathrm{J} \mathrm{s}^{-1}\right)$, expressed as:

$$
E=\beta \times R \times S
$$

where $\beta$ is the assimilation efficiency, $R$ the area grazed per unit time $\left(\mathrm{mm}^{2} \mathrm{~s}^{-1}\right)$, and $S$ the standing crop per unit area $\left(\mathrm{J} \mathrm{mm}^{-2}\right)$.

Limpets are assumed to forage systematically and remove all the encountered food over an area $A$ :

$$
A=T_{\mathrm{F}} \times R
$$

If, at the beginning of a foraging period, the edge of a feeding patch is located at a distance $D_{\text {start }}$ from the home, at the end of the period the distance will be increased to a new value $D_{\text {end }}$ (Fig. 1c). Given the geometry of the system, the area removed during foraging can be also expressed as:

$$
A=\left(D_{\text {end }}^{2} \times \theta / 2\right)-\left(D_{\text {start }}^{2} \times \theta / 2\right)
$$

where $\theta$ is the angular width of the sector. From Eq. (6) it follows that:

$$
D_{\text {end }}=\sqrt{D_{\text {start }}^{2}+2 A / \theta}
$$

Depletion has important consequences for the expectation of energetic return from a revisit to a sector. In fact, since the outer edge of a sector changes from $D_{\text {start }}$ to $D_{\text {end }}$ after the visit, this determines an increase in the distance to be travelled by a limpet to revisit that patch and a general increase in the average distance of all food patches from home. This effect is modelled with the following equations.

The initial distances, $D$, of all the patches from the home site are extracted from a normal distribution with mean $\mu_{D}$ and standard deviation $\sigma_{D}$. However, the average distance from the home is $\mu_{D}$ updated after each bout, to keep track of depletion caused by limpet foraging (Eqs. $6 \& 7$ ). The model assumes that the standing crop value $(S)$ of each sector follows a normal distribution with mean $\mu_{\mathrm{S}}$ and standard deviation $\sigma_{\mathrm{S}}$. When a sector is visited during 2 consecutive times $(t-1$ and $t)$, its standing crop is determined as:

$$
S_{t}=\mu_{\mathrm{s}}+\varepsilon+\alpha\left(S_{t-1}-\mu_{\mathrm{s}}\right)
$$

where $\varepsilon$ is a random normal deviate with mean 0 and standard deviation:

$$
\sigma_{\varepsilon}=\sqrt{\sigma_{\mathrm{S}}^{2}\left(1-\alpha^{2}\right)}
$$

and $\alpha$ is an autocorrelation coefficient $(-1 \leq \alpha \leq 1)$. This allows the modelling of different levels of correlation in energy reward from successive visits to the same sector. When $\alpha=1$, the standing crop of the sector remains the same from time $t-1$ to $t$. On the contrary, when $\alpha=0$ there is no relation between $S_{\mathrm{t}-1}$ and $S_{\mathrm{t}}$ and, finally, for $\alpha<0$ higher than average rewards are followed by lower than average rewards.

Expected energetic gains for returning to the lastvisited sector can be basically derived from Eq. (3). Since $\varepsilon$ in Eq. (8) above has a mean of 0 , expected returns can be expressed as:

$$
\hat{G}_{\text {return }}=\left(T-2 D_{\text {last }} / V\right) \times\left(\bar{E}+\alpha\left[E_{\text {last }}-\bar{E}\right]\right)-T \mathrm{C}
$$

where $\bar{E}$ is the average rate of energy extraction and $D_{\text {last }}$ and $E_{\text {last }}$ are the distance from the centre of activity of the outer edge and the rate of energy extraction from the previously visited patch, respectively. Eq. (10) follows directly from the general Eq. (8), letting $\varepsilon=0$, $S_{\mathrm{t}-1}=E_{\text {last }}$, and $\mu_{\mathrm{S}}=\bar{E}$.

If the forager acts without knowledge of any autocorrelation of rewards then the above equation simplifies to:

$$
\hat{G}_{\text {return }}=\left(T-2 D_{\text {last }} / V\right) \times E_{\text {last }}-T \mathrm{C}
$$

The expected energy return from the environment is:

$$
\hat{G}_{\mathrm{all}}=(T-2 \bar{D} / V) \times \bar{E}-T \mathrm{C}
$$

which represents the average energy gain which could be obtained from a patch located at a distance equal to the average distance of all patches $(\bar{D})$ and allowing a rate of energy extraction equal to the average value of the whole environment $(\bar{E})$. In synthesis, this quantity represents the expectation of rewards from choosing any sector at random.

Based on Eqs. (10) to (12) above, 3 decision rules of increasing complexity were compared:

(1) Random choice rule (RC): at the beginning of a foraging bout a limpet selects a sector at random, irrespective of prior rewards.

(2) Marginal value rule with unknown autocorrelation (MVU): a limpet revisits the previously visited sector if:

$$
\hat{G}_{\text {return }}>\hat{G}_{\text {all }}
$$

otherwise it chooses any sector at random. $\hat{G}_{\text {return }}$ is here computed according to Eq. (11).

(3) Marginal value rule with known autocorrelation (MVK): as MVU but with $\hat{G}_{\text {return }}$ computed according to Eq. (10). In synthesis, a forager adopting this strategy is assumed to be able to perfectly perceive and keep track of changes in energy return from successive visits to the same patch.

Parameter values and sensitivity analysis. The model was run using values for energetic costs and 
rates of ingestion for Patella vulgata, since this is the species for which these values are best known. Energy costs (computed as the sum of mucus production and respiration rates), rasping rate and area cleared per radula stroke were computed for a $40 \mathrm{~mm}$ shell length limpet. Costs of respiration were from Houlihan \& Newton (1978) and costs of mucus production were those measured by Davies et al. (1990). While foraging outside of the home scar, $P$. vulgata alternates fast and slow movements, during which rasping is almost continuous. However, although estimates of both respiration and mucus production for 2 alternative states (i.e. limpets sitting on their home scar and limpets foraging outside the home) are available, there is no information on the variation of energy costs incurred by limpets while moving at different speeds (e.g. when travelling to and when foraging inside a patch). Due to this difficulty, total cost of foraging, TC, was computed irrespective of how much of that trip was spent on travel to a patch and how much was spent actually inside the patch. More details and sources of variable values are listed in Burrows et al. (2000). Total time available for foraging was assumed to be $21600 \mathrm{~s}$, corresponding to $6 \mathrm{~h}$. A complete list of values used is shown in Table 1.

A sensitivity analysis was performed to determine the role of the different environmental factors in the final cumulative energy intake obtained by specimens adopting one of the 3 different strategies (RC, MVU, MVK). The factors considered were:

(1) Average standing crop. We used 3 average energy contents of foraging grounds: $\mu_{\mathrm{S}}=0.1,0.3,0.5$ $\left(\mathrm{J} \mathrm{mm}^{-2}\right)$, simulating low, medium and high richness of algal pastures, respectively (see Burrows et al. 2000).
(2) Variability in standing crop. For each average energy value, 3 different levels of variability (as standard deviation $\sigma_{\mathrm{S}}$ ) were tested, corresponding to 0,30 and $70 \%$ of the average.

(3) Distance from home of foraging patches. Initial sector radii were extracted from a normal distribution with mean $\mu_{\mathrm{D}}=200(\mathrm{~mm})$ and 2 different standard deviation values: $\sigma_{\mathrm{D}}=0$ and $\sigma_{\mathrm{D}}=100$. These values broadly correspond to average value and variability levels observed in Patella vulgata foraging excursions (e.g. Chelazzi et al. 1994, Della Santina et al. 1995).

(4) Autocorrelation. To simulate different degrees of correlation between the energy returns from successive visits to the same foraging sector, the autocorrelation coefficient $\alpha$ was varied from -1 to 0 and +1 , in steps of 0.2 .

For each specimen, simulations were run for 100 foraging bouts with 36 sectors (Fig. 1). The number of 36 sectors was calibrated on the geometry of the system and the dimension of model limpets. If we assume a limpet forages up to a distance of 20 to $25 \mathrm{~cm}$ from the home scar (see e.g Della Santina et al. 1995), the width of the arc at that distance will be about $44 \mathrm{~mm}$, a dimension comparable with the size of model limpets (40 mm). Long-term energy return, expressed as average cumulative energy gain per foraging bout, was calculated at the end of each simulation. The behaviour of 100 specimens was simulated for each combination of parameter values. The relative importance of the different factors on the final energy return obtained by limpets adopting the 3 different strategies was expressed as percentage of total variance explained in an ANOVA framework. However, this procedure was used only to give an indication of the likely effect of each factor, and no formal statistical test was attempted.

Table 1. Symbols and values for variables used in the model. (a) Values representing limpet activity and time budgets; (b) values representing environmental conditions, used in the sensitivity analysis. Sources of data are listed in the text

\begin{tabular}{|llll|}
\hline Symbols & Units & \multicolumn{1}{c|}{ Definition } & Value \\
\hline (a) Limpet activity & & & Assimilation efficiency \\
$\beta$ & & Metabolic cost & 0.45 \\
$C$ & $\left(\mathrm{~J} \mathrm{~s}^{-1}\right)$ & Time available for foraging & 0.003 \\
$T$ & $(\mathrm{~s})$ & 21600 \\
$V$ & $\left(\mathrm{~mm} \mathrm{~s}^{-1}\right)$ & Travel speed & 0.05 \\
$R$ & $\left(\mathrm{~mm}^{2} \mathrm{~s}^{-1}\right)$ & Area scraped while foraging & 0.252 \\
$\theta$ & $\left(\mathrm{degrees}^{2}\right)$ & Angular sector foraged & 10 \\
$(\mathbf{b})$ Environment & & & 200 \\
$\mu_{\mathrm{D}}$ & $(\mathrm{mm})$ & Average patch distance from the home & 0,100 \\
$\sigma_{\mathrm{D}}$ & $(\mathrm{mm})$ & Standard deviation of patch distance from the home & $0.1,0.3,0.5$ \\
$\mu_{\mathrm{S}}$ & $\left(\mathrm{J} \mathrm{mm}^{-2}\right)$ & Average standing crop & $0,30 \%, 70 \%$ of $\mu_{\mathrm{S}}$ \\
$\sigma_{\mathrm{S}}$ & $\left(\mathrm{J} \mathrm{mm}^{-2}\right)$ & Standard deviation of standing crop value & -1 to +1 \\
$\alpha$ & & Autocorrelation, the dependence of rewards on previous visits & \\
\hline
\end{tabular}




\section{RESULTS}

A typical simulation for a random choice forager (i.e. adopting the $\mathrm{RC}$ rule) is shown in Fig. 2a, with a corresponding simulation for a forager operating by the MVK rule in Fig. $2 b$. The proportion of revisits to the previous sector is small for the random forager (around the expected value of 0.028 , i.e $1 / 36$ sectors), while much higher values, in the range of 0.55 to 0.7 , were obtained for the forager adopting the MVK rule. Moreover, the energy gain attained by this forager reached a higher level than that obtained by the random forager. Depletion by limpets causes an increase in foraging radius and hence a decrease in energy return, which is not evident in either of these examples. However this effect can be much more pronounced in other simulations and depends on the ratio between energy content of food patches and energy cost of activity. Finally, an evident decrease in energy return would be determined if a greater number of foraging bouts were simulated.

The results of the sensitivity analysis are shown in Table 2 for the 3 different $\sigma_{\mathrm{S}}$ levels and different standing crop values. The importance of each factor in

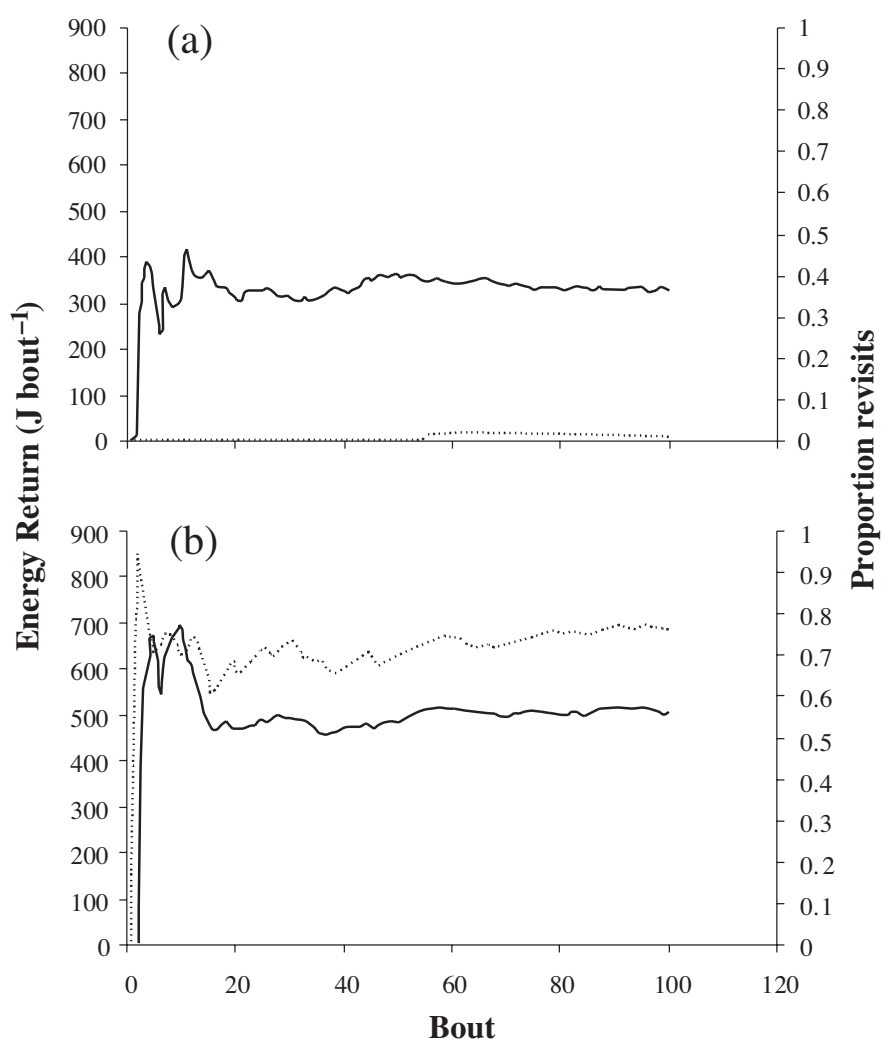

Fig. 2. Examples of simulation results for specimens adopting either (a) RC or (b) MVK rule. (-) Long-term average energy return; $(\cdots . . . \cdot)$ proportion of revisits to the previous patch. Parameter values: $\mu_{\mathrm{D}}=200, \sigma_{\mathrm{D}}=100 ; \mu_{\mathrm{S}}=0.5, \sigma_{\mathrm{S}}=70 \% ; \alpha=0.8$
Table 2. Relative effect of the different factors on energy return from foraging bouts by model $40 \mathrm{~mm}$ Patella vulgata, expressed as percentage of total variance. Values are shown separately for the 3 standing crop $\left(\mu_{\mathrm{S}}\right)$ values employed. $\mathrm{df}$, degrees of freedom. (a) $\sigma_{\mathrm{S}}=0$; (b) $\sigma_{\mathrm{S}}=30 \% \mu_{\mathrm{S} i}$ (c) $\sigma_{\mathrm{S}}=70 \% \mu_{\mathrm{S}}$.

Strat, behavioural strategy; other symbols as in Table 1

\begin{tabular}{|c|c|c|c|c|}
\hline \multirow[t]{2}{*}{ Source } & \multirow[t]{2}{*}{ df } & \multicolumn{3}{|c|}{ Variance explained (\%) } \\
\hline & & $\mu_{\mathrm{S}}=0.1$ & $\mu_{\mathrm{S}}=0.3$ & $\mu_{\mathrm{S}}=0.5$ \\
\hline \multicolumn{5}{|l|}{ (a) $\sigma_{\mathrm{S}}=\mathbf{0}$} \\
\hline Strat & 2 & 20.05 & 15.45 & 10.39 \\
\hline$\alpha$ & 8 & 1.20 & 0.76 & 0.01 \\
\hline$\sigma_{\mathrm{D}}$ & 1 & 72.16 & 77.20 & 87.27 \\
\hline Strat $\times \alpha$ & 16 & 1.12 & 1.76 & 0.24 \\
\hline Strat $\times \sigma_{\mathrm{D}}$ & 2 & 2.84 & 1.88 & 1.90 \\
\hline$\alpha \times \sigma_{\mathrm{D}}$ & 8 & 0.98 & 1.06 & 0.04 \\
\hline Strat $\times \alpha \times \sigma_{\mathrm{D}}$ & 16 & 1.67 & 1.90 & 0.14 \\
\hline \multicolumn{5}{|l|}{ (b) $\sigma_{\mathrm{S}}=30 \%$} \\
\hline Strat & 2 & 22.64 & 22.42 & 36.85 \\
\hline$\alpha$ & 8 & 24.47 & 27.64 & 6.40 \\
\hline$\sigma_{\mathrm{D}}$ & 1 & 14.68 & 12.75 & 49.82 \\
\hline Strat $\times \alpha$ & 16 & 35.59 & 35.66 & 5.57 \\
\hline Strat $\times \sigma_{D}$ & 2 & 0.95 & 0.18 & 0.99 \\
\hline$\alpha \times \sigma_{\mathrm{D}}$ & 8 & 0.75 & 0.28 & 0.18 \\
\hline Strat $\times \alpha \times \sigma_{\mathrm{D}}$ & 16 & 0.92 & 1.06 & 0.19 \\
\hline \multicolumn{5}{|l|}{ (c) $\sigma_{\mathrm{S}}=70 \%$} \\
\hline Strat & 2 & 20.13 & 21.70 & 55.05 \\
\hline$\alpha$ & 8 & 38.40 & 36.32 & 21.35 \\
\hline$\sigma_{\mathrm{D}}$ & 1 & 1.91 & 2.55 & 12.26 \\
\hline Strat $\times \alpha$ & 16 & 38.99 & 39.03 & 10.75 \\
\hline Strat $\times \sigma_{\mathrm{D}}$ & 2 & 0.22 & 0.13 & 0.35 \\
\hline$\alpha \times \sigma_{\mathrm{D}}$ & 8 & 0.17 & 0.11 & 0.10 \\
\hline Strat $\times \alpha \times \sigma_{D}$ & 16 & 0.19 & 0.17 & 0.14 \\
\hline
\end{tabular}

determining the cumulative energy intake is shown as the percentage of total variance explained. In the absence of any variability in the energy content of each patch $\left(\sigma_{\mathrm{S}}=0\right.$, Table $\left.2 \mathrm{a}\right)$, the greatest part of the variance $(>70 \%)$ was explained by the variability in distance from home of the food patches $\left(\sigma_{\mathrm{D}}\right)$, and a further 20 to $10 \%$ was explained by the adopted strategy. The importance of $\sigma_{\mathrm{D}}$ increases for increasing standing crop, while the importance of the factor strategy decreases. The maximal differences in the final energy returns obtained under the 3 strategies and the $2 \sigma_{\mathrm{D}}$ levels were, however, low and corresponded to about 6 to $8 \%$ of total cost of activity (Fig. 3).

This picture becomes more complex for increasing variability in food reward. Table $2 \mathrm{~b}$ shows the results obtained when $\sigma_{\mathrm{S}}=30 \% \mu_{\mathrm{S}}$. When standing crop is low, the greatest contribution to variance is given by the interaction Strat $\times \alpha(\sim 36 \%)$, while strategy and autocorrelation per se explain about 23 and $24 \%$ of total variance, respectively. As standing crop increases the majority of variance is explained by the variability in distance from the home $\sigma_{\mathrm{D}}(\sim 50 \%)$ and strategy $(\sim 37 \%)$. A still different pattern of variation was evi- 


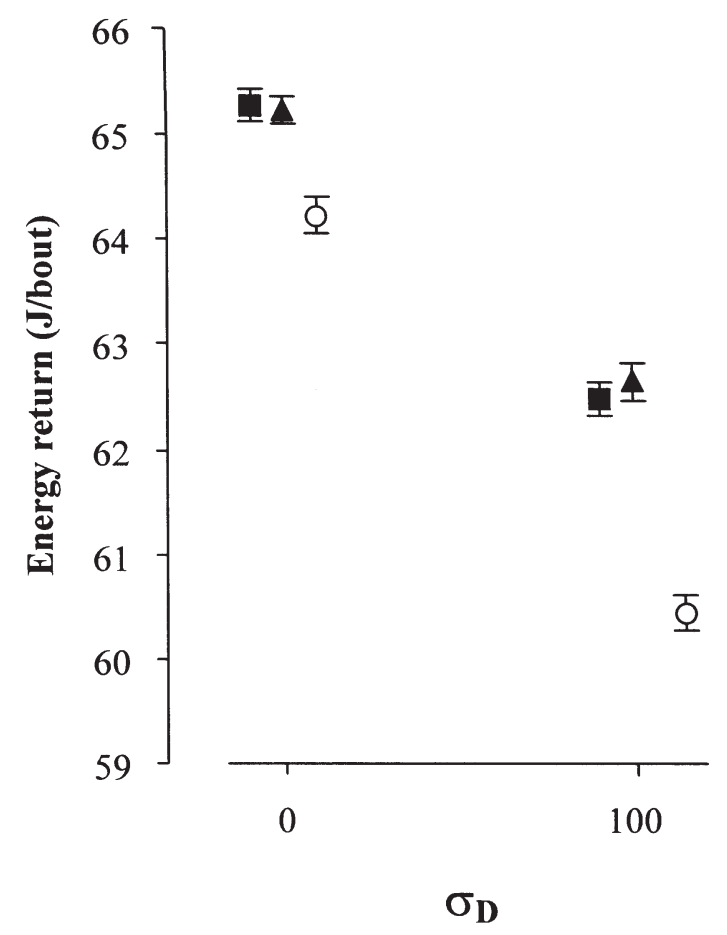

Fig. 3. Average energy return obtained from specimens adopting the 3 strategies for changing $\sigma_{\mathrm{D}}$ values. (O) RC rule; (ム) MVU rule; (ם) MVK rule. Other parameter values: $\mu_{\mathrm{D}}=$ $200, \mu_{\mathrm{S}}=0.1, \sigma_{\mathrm{S}}=0$ dent when using higher variability levels $\left(\sigma_{\mathrm{S}}=70 \%\right.$ of the standing crop value, Table 2c). For lower standing crop values, the 2 major sources of variance are still represented by the interaction Strat $\times \alpha$ and autocorrelation, while for increasing standing crop values $\left(\mu_{\mathrm{S}}=\right.$ $0.5)$ the greatest part of variance $(\sim 55 \%)$ is explained by the adopted strategy and a further $21 \%$ by autocorrelation between successive rewards.

The role of the different factors can be better understood by looking at some examples. Fig. 4 compares the average energetic returns obtained from foragers adopting the 3 rules, for different variability $\left(\sigma_{\mathrm{S}}\right)$ and predictability $(\alpha)$ of rewards when using the 2 extreme standing crop values (i.e. $\mu_{\mathrm{S}}=0.1$, Fig. $4 \mathrm{a}-\mathrm{C}_{i} \mu_{\mathrm{S}}=0.5$, Fig. $4 \mathrm{~d}-\mathrm{f}$ ). When variability is set to $\sigma_{\mathrm{S}}=0$ (Fig. $4 \mathrm{a}, \mathrm{d}$ ), the difference in energy return obtained with the 3 rules was very small and not at all affected by autocorrelation in reward. On the contrary, as variability increases, a difference among the 3 strategies becomes evident. In this case, the outcome of the $\mathrm{RC}$ rule is still not affected by changes in the autocorrelation among successive visits, neither for intemediate $\left(\sigma_{\mathrm{S}}=30 \% \mu_{\mathrm{S}}\right.$, Fig. $4 \mathrm{~b}, \mathrm{e})$, nor for higher variability in food $\left(\sigma_{\mathrm{S}}=\right.$ $70 \% \mu_{\mathrm{S}}$, Fig. $\left.4 \mathrm{c}, \mathrm{e}\right)$. On the contrary, the MVU strategy performs better than the RC for $\alpha>0$, but worst for $\alpha<$ 0 , and this difference becomes more pronounced for increasing $\sigma_{\mathrm{S}}$ values (compare Fig. $4 \mathrm{~b}$ vs c and e vs f).
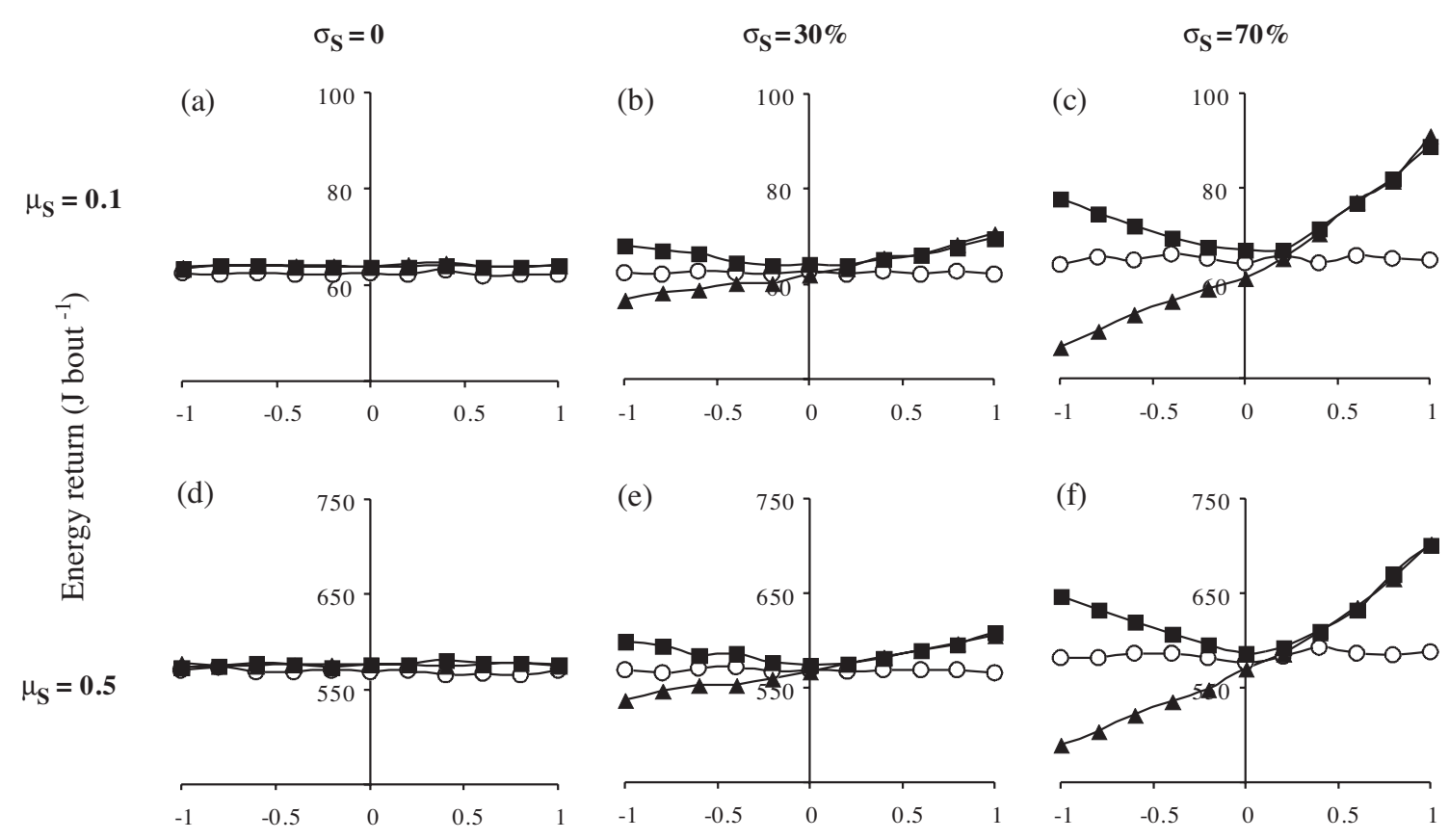

Autocorrelation $\alpha$

Fig. 4. Dependence of average energetic return on variability $\left(\sigma_{\mathrm{S}}\right)$ and predictability (as $\alpha$ ) of reward, obtained by foragers operating different decision rules. (O) RC rule; $(\boldsymbol{\square})$ MVK rule; $(\boldsymbol{\Delta})$ MVU rule. Other parameter values: $(\mathrm{a}-\mathrm{C}) \mu_{\mathrm{S}}=0.1,(\mathrm{~d}-\mathrm{f}) \mu_{\mathrm{S}}=0.5$. $\mu_{\mathrm{D}}=200, \sigma_{\mathrm{D}}=100$ 
Finally, the MVK rule always performs better than the $\mathrm{RC}$ rule and this difference becomes much more pronounced for increasing $|\alpha|$ values and for increasing $\sigma_{\mathrm{s}}$. Using different standing crop values does not alter the overall picture, but causes an upward (higher SC values) or a downward (lower SC values) shift in the curves.

\section{DISCUSSION}

It has long been recognised that a periodic return to a central place might facilitate the spatial organisation of foraging, allowing a more efficient exploitation of radially distributed food patches, provided that animals are able to establish suitable behavioural strategies (Stephens \& Krebs 1986, Bell 1991). The outcomes of 3 possible strategies for exploiting radially distributed resources in homing molluscs were compared in this study. The marginal value-based rule, coupled with the ability to perceive and correctly keep track of correlations between successive visits (MVK rule), performed better than the random choice rule, provided that variability in patch content was not null and that there was autocorrelation in energy returns from successive visits to the same patch. In particular, the relative advantage of the MVK strategy over the simple random choice rule increased with increasing variability and with increasing absolute correlation $(|\alpha|>0)$ in energy rewards between successive visits. The other marginal value-based rule, MVU, based only on the 'memory' of the energy content of the previous patch may prove equally as adaptive as the more complex MVK, when the rewards of successive visits to the same patch are positively autocorrelated. In contrast, negative autocorrelation (such that higher than average rewards are followed by lower than average gains) may result in an energy intake much lower than that granted by a simple random choice. Finally, the random choice strategy, RC, may give energy returns comparable with those of the other rules when variability in patch energy content is null $\left(\sigma_{\mathrm{S}}=0\right)$, or when there is no correlation between successive visits $\left(\sigma_{\mathrm{S}} \neq\right.$ $0, \alpha=0$ ). In the first case, however, the RC rule always gave slightly lower values than the other rules, while in the second case the constant rank MVK $>$ RC $>$ MVU was observed.

The absence of any autocorrelation and the presence of negative autocorrelation between successive visits seem to be rather limited features of specific environments, such as rapidly changing and ephemeral habitats, where the predictability of food sources is low. Moreover, a lower predictability of food sources could also be a consequence of the spatial arrangement of the food patches and the home scars of limpets. In intertidal environments, which generally consist of narrow habitat belts, individual limpets are often highly packed and inter-individual distances may be shorter than the distance a forager is able to move during a single activity bout. Due to this arrangement, the patches located at the edge of an individual foraging area may thus be 'shared' among neighbouring individuals. In this case, the probability of finding that a 'good' patch has been depleted by other foragers increases as a function of its net energy content (which renders it more likely chosen) and of the density of individuals. In similar circumstances, autocorrelation between successive visits may be very low when not negative, making a negative autocorrelation between successive visits to the same location not unlikely.

Direct tests of the model are difficult, since long-term recordings of the spatial arrangement of foraging activity in molluscs, and the simultaneous assessment of the energy content and degree of patchiness of the microbial film at the spatial scale experienced by individual limpets are scarce. Despite the difficulty of direct comparisons of the model with behaviour in specific resource distributions, some general insights can be obtained from less direct evidence. Two broad patterns of the frequency with which a given individual returns to a location visited during the preceding foraging excursion can be recognised from available recordings of the behaviour of marine homing molluscs. The first, observed in the gastropods Onchidium spp. (McFarlane 1980) and Patella vulgata (Chelazzi et al. 1998), and the chiton Acanthopleura gemmata (Chelazzi et al. 1987), consists of a non-random revisiting of previously exploited foraging patches. In these species, in fact, a significant proportion of individuals returned to a spatial location visited during the immediately preceding activity period (e.g. $40 \%$ in P. vulgata). The opposite behavioural scheme consists of a cropping pattern based on random angular selection. This behaviour has been described in the Mediterranean high shore limpet $P$. rustica (Chelazzi et al. 1994), but similar findings have also been reported for the 2 pulmonate limpets Siphonaria normalis and $S$. alternata (Cook \& Cook 1981). The high percentage of revisiting of a previous patch observed in the first group of species may suggest that these adopt experience-based rules, similar to MVK or MVU proposed here, while the second group shows a behaviour more consistent with a random choice. Generalisations at the species level are, however, difficult and caution must be exercised when assigning a fixed behavioural repertoire to a given species. For example, in a study of the foraging activity of $P$. vulgata in an Irish Sea Lough, Williams \& Morritt (1991) reported that about $26 \%$ of the limpets moved in the same direction as a previous bout and that $48 \%$ recrossed a previous path but, at 
the same time, generally ended their foraging activity in different areas on each trip.

These 2 classes of behaviour broadly agree with what is known about the spatial distribution of algal/microbial food patches in the study areas. For example, in NE Atlantic benthic communities, where Patella vulgata predominates, patchiness seems to be a common feature at different spatial scales (review in Hawkins et al. 1992), including a small scale comparable with that experienced by individual limpets while foraging (e.g. Hill \& Hawkins 1990, 1991). The general environmental characteristics of these shores seem to be comparable with conditions promoting rule-based behaviour over random choice. The alternative behavioural pattern is represented by the Mediterranean limpet $P$. rustica, which scatters its foraging excursion in a random fashion (Chelazzi et al. 1994). This species dominates the upper part of the mid-littoral (Della Santina et al. 1993) along Mediterranean rocky shores and concentrates its foraging activity in stormy periods, when wave action exceeds a given threshold (Della Santina \& Chelazzi 1991). During these confined temporal windows this species moves to forage on relatively rich and unexploited upper-shore patches, which are usually not accessible to grazers during a calm sea. These areas, mainly dominated by epi- and endolithic cyanobacteria, are likely to approach a condition of relatively low variability, given their limited exploitation status (Della Santina et al. 1993). Quantitative assessments of the degree of short-scale patchiness are not available in this case, but previous observation (Della Santina 1990) has suggested the existence of an almost uniform layer. In this situation, the random-like choice operated by this species, characterised by a very low rate of revisiting the previous patch, seems to be in agreement with the expectations of the RC rule which, in the absence of variability in food sources, may perform very similarly to more complex ones. Extreme caution is, however, needed in this specific case, because, given the absence of direct measurement of cyanobacteria biomass, it is not possible to completely exclude the existence of an unrecognised patchiness in an apparently uniform microbial layer (e.g. Nagarkar \& Williams 1997, 1999).

The model proposed in this paper is conceptually simple and, as most models, makes a number of assumptions that may influence the predicted patterns of patch choice. A first critical assumption is that animals were supposed to have some 'memory' of the spatial arrangements and energy value of food patches and were able to keep track of their changes after subsequent visits. The available literature on spatial memory in animals is comprehensive, and specific traits and features have been described for different groups (e.g. Healy 1998). In the case of molluscs, information can be contained in mucous trails, which can be considered as an 'external memory system' (Focardi et al. 1985, Chelazzi 1992). The exact mechanisms of information storage in mucous trails are still poorly understood; however, there is strong evidence of the existence of such a system (see Davies \& Hawkins 1998, for a review). Trail following is a widespread orienting mechanism in molluscan behaviour and individual ability to follow previously laid trails has been demonstrated in diverse contexts, such as individual or collective homing, mating, prey or patch location (Chelazzi et al. 1988, Davies \& Hawkins 1998 for reviews). Evidence of the ability to follow trails laid several days earlier has been reported for several species, including Patella vulgata (e.g. Cook et. al. 1969, Thomas 1973). Interestingly, Chelazzi et al. (1998) reported for P. vulgata that when the outward and homeward branch of a foraging path diverged, the next outward excursion usually overlapped with the homeward branch of the previous excursion, suggesting that some information on the quality of the encountered food patches is contained in the trails. The recognised long-term persistence of mucous trails in the field, which in the case of P. vulgata may approach 80 d (Davies et al. 1992a), supports the hypothesis that the home scar of homing limpets is surrounded by a complex network of trails, whose information content may be high. This suggests that the choices faced by a foraging limpet could be much more complex than those hypothesised in this study. If the home scar of each specimen is in fact surrounded by a network of trails, laid at different times and with information on several patches, a limpet may have to compare the potential benefits from several alternative patches and not simply choose between the last visited patch and a randomly selected one. In addition, following a previous trail may allow the individual to partly reingest laid mucus. Due to its high energy content and the ability to trap microalgae and enhance microbial growth (e.g. Connor \& Quinn 1984, Connor 1986, Davies et al. 1992b, Davies \& Williams 1995), mucus reingestion may constitute an extra value, not considered in our model, in revisiting a prior location. Interestingly, trapping of microalgal particles is usually maximal after a short time (a few hours: Davies et al. 1992b, Santelices \& Bobadilla 1996) and this could represent a further stimulus to return to recently visited patches.

A further assumption is that resource renewal was considered to be negligible for all the duration of the simulated study period (100 foraging bouts $\cong 100 \mathrm{~d}$ ). This is of course a critical point, since under natural conditions renewal of resource will always take place over a similar time scale. Modelling algal regrowth may potentially allow more specific predictions, but at the expense of generality and simplicity, due to the 
increased number of variables (each with a range of possible values) to be introduced. The rate of regrowth over cleared surfaces may in fact change according to a complex mixture of different factors (e.g. season, level on the shore, rate of removal; see e.g. Underwood 1984, Hill \& Hawkins 1991, Nagarkar \& Williams 1999, Thompson et al. 2000, Jenkins et al. 2001) and was not considered here for simplicity. In any case, the results of the model, showing no consistent decrease in the energy returns with increasing time, suggest that this effect may be ignored, at least in this preliminary step. The dynamics of microbial film growth, and their effects on the behaviour of intertidal grazers, need a greater field study and modelling effort to be better understood.

Similarly, simplifying assumptions have been made concerning the nature of food patches, such as their distance from the central place or their energy content. All these values were modelled on the basis of normal distributions but, under specific environmental situations, other distributions (e.g. Poisson or negative binomial) may be more realistic. Again the aim of the model was to provide general insights on the organisation of central place foraging activity and not to provide specific predictions for particular conditions.

In conclusion, the results of this study allow the evaluation of different strategies for exploiting radially distributed food patches. Apart from possible modelling improvements, as indicated above, advancements in field data collection are required to fully ascertain the behavioural rules actually employed by homing molluscs in the spatial organisation of their foraging activity. In particular, more medium- to long-term records of the spatial organisation of the activity of single individuals are required, together with detailed simultaneous information on the small-scale distribution and energy content and quality of the microbial film around the home scars. We hope that this model can be used to stimulate and address further work in these directions.

Acknowledgements. MTB was supported by the Università degli Studi di Firenze during the development of the model in Firenze. G. A. Williams and M. G. Chapman commented on an earlier draft of the manuscript.

\section{LITERATURE CITED}

Armstrong DP, Lee Gass C, Sutherland GD (1987) Should foragers remember where they've been? Explorations of a simulation model based on the behavior and energetics of territorial hummingbirds. In: Kamil AC, Krebs JR, Pulliam HR (eds) Foraging behavior. Plenum Press, New York, p 563-586

Bell WJ (1991) Searching behaviour. The behavioural ecology of finding resources. Chapman \& Hall, London
Burrows MT, Santini G, Chelazzi G (2000) A state-dependent model of activity patterns in homing limpets: balancing energy returns and mortality risks under constraints on digestion. J Anim Ecol 69:290-300

Chapman MG, Underwood AJ (1992) Foraging behaviour of marine benthic grazers. In: John D, Hawkins SJ, Price J (eds) Plant-animal interactions in the marine benthos. Clarendon Press, Oxford, p 289-317

Chelazzi G (1992) Invertebrates (excluding arthropods). In: Papi $F$ (ed) Animal homing. Chapman \& Hall, London, p 19-43

Chelazzi G, Della Santina P, Parpagnoli D (1987) Trail following in the chiton Acanthopleura gemmata: operational and ecological problems. Mar Biol 95:539-545

Chelazzi G, Focardi S, Deneubourg JL (1988) Analysis of movement patterns and orientation mechanisms in intertidal chitons and gastropods. In: Chelazzi G, Vannini M (eds) Behavioural adaptation to intertidal life. Plenum Press, New York, p 173-184

Chelazzi G, Terranova G, Della Santina P (1990) A field technique for recording the activity of limpets. J Molluscan Stud 56:595-600

Chelazzi G, Della Santina P, Santini G (1994) Rhythmical timing and spatial scattering of foraging in a homer limpet (Patella rustica). Behav Ecol 5:288-292

Chelazzi G, Santini, G, Della Santina P (1998) Route selection in the foraging of Patella vulgata (Mollusca: Gastropoda). J Mar Biol Assoc UK 78:1223-1232

Connor VM (1986) The use of mucous trails by intertidal limpets to enhance food resources. Biol Bull (Woods Hole) 171:548-564

Connor VM, Quinn JF (1984) Stimulation of food species growth by limpet mucus. Science 225:1843-844

Cook A, Bamford OS, Freeman JB, Teidman DJ (1969) A study on the homing habit of the limpet. Anim Behav 17: 330-339

Cook SB, Cook CB (1981) Activity pattern in Siphonaria populations: heading choice and the effects of size and grazing interval. J Exp Mar Biol Ecol 49:69-80

Davies MS, Hawkins SJ (1998) Mucus from marine molluscs. Adv Mar Biol 34:1-71

Davies MS, Williams GA (1995) Pedal mucus of a tropical limpet, Cellana grata (Gould) - energetics, production and fate. J Exp Mar Biol Ecol 186:77-87

Davies MS, Hawkins SJ, Jones HD (1990) Mucus production and physiological energetics in Patella vulgata L. J Molluscan Stud 56:499-503

Davies MS, Jones HD, Hawkins S (1992a) Physical factors affecting the fate of pedal mucus produced by the common limpet Patella vulgata. J Mar Biol Assoc UK 72:633-643

Davies MS, Hawkins SJ, Jones HD (1992b) Pedal mucus and its influence of microbial food supply of two intertidal gastropods, Patella vulgata L. and Littorina littorea (L.). J Exp Mar Biol Ecol 161:57-77

Della Santina P (1990) Eco-etologia dei Patellidae (Mollusca: Gastropoda) sul litorale tirrenico. PhD dissertation, University of Florence

Della Santina P, Chelazzi G (1991) Temporal organization of foraging in two Mediterranean limpets, Patella rustica (L.) and Patella caerulea (L.). J Exp Mar Biol Ecol 153:75-85

Della Santina P, Sonni C, Sartoni G, Chelazzi G (1993) Food availability and diet composition of three coexisting Mediterranean limpets (Patella spp.). Mar Biol 116:87-96

Della Santina P, Santini G, Chelazzi G (1995) Factors affecting variability of foraging excursions in a population of Patella vulgata (Mollusca, Gastropoda). Mar Biol 122:265-270

Denny M (1980) Locomotion: the cost of gastropod crawling. Science 208:1208-1212 
Focardi S, Deneubourg JL, Chelazzi G (1985) The external memory of intertidal molluscs: a theoretical study of trailfollowing. In: Capasso V, Grosso E, Paveri-Fontana SL (eds) Mathematics in biology and medicine. Springer Verlag, Berlin, p 54-59

Hartnoll RG, Wright JR (1977) Foraging movements and homing in the limpet Patella vulgata. Anim Behav 25:806-810

Hawkins SJ, Hartnoll RG (1983) Grazing of intertidal algae by marine invertebrates. Oceanogr Mar Biol Annu Rev 21: 195-282

Hawkins SJ, Hartnoll RG, Kain JM, Norton TA (1992) Plantanimal interactions on hard substrata in the North-east Atlantic. In: John D, Hawkins SJ, Price J (eds) Plantanimal interactions in the marine benthos. Clarendon Press, Oxford, p 1-32

Healy S (1998) Spatial representation in animals. Oxford University Press, Oxford

Hill AS, Hawkins SJ (1990) An investigation of methods for sampling microbial films on rocky shores. J Mar Biol Assoc UK 70:77-88

Hill AS, Hawkins SJ (1991) Seasonal and spatial variation of epilithic microalgal distribution and abundance and its ingestion by Patella vulgata on a moderately exposed rocky shore. J Mar Biol Assoc UK 71:403-423

Houlihan DF, Newton JRL (1978) Respiration of Patella vulgata on the shore. In: McClusky DJ, Berry AJ (eds) Physiology and behaviour of marine organisms, Proc 12th Eur Mar Biol Symp. Pergamon Press, Oxford, p 39-46

Jenkins SR, Arenas F, Arrontes J, Bussell J and 10 others (2001) European-scale analysis of seasonal variability in limpet grazing activity and microalgal abundance. Mar Ecol Prog Ser 211:193-203

Little C (1989) Factors governing patterns of foraging activity in littoral marine herbivorous molluscs. J Molluscan Stud

Editorial responsibility: Roger Hughes (Contributing Editor), Bangor, UK
55:273-284

McFarlane ID (1980) Trail-following and trail-searching behaviour in homing of the intertidal gastropod mollusc, Onchidium verruculatum. Mar Behav Physiol 7:95-108

McFarlane ID (1981) In the intertidal homing gastropod Onchidium verruculatum (Cuv.) the outward and homeward trails have a different information content. J Exp Mar Biol Ecol 51:207-218

Nagarkar S, Williams GA (1997) Comparative techniques to quantify cyanobacteria dominated epilithic biofilms on tropical rocky shores. Mar Ecol Prog Ser 154:281-291

Nagarkar S, Williams GA (1999) Spatial and temporal variation of cyanobacteria-dominated epilithic communities on a tropical shore in Hong Kong. Phycologia 38:385-393

Santelices B, Bobadilla M (1996) Gastropod pedal mucus retains seaweed propagules. J Exp Mar Biol Ecol 197: $251-261$

Stephens DW, Krebs JR (1986) Foraging theory. Princeton University Press, Princeton

Thomas RF (1973) Homing behaviour and movement rhythms in the pulmonate limpet, Siphonaria pectinata L. Proc Malacol Soc Lond 40:303-311

Thompson RC, Roberts MF, Norton TA, Hawkins SJ (2000) Feast for famine for intertidal grazing molluscs: a mismatch between seasonal variations in grazing intensity and the abundance of microbial resources. Hydrobiologia 440:357-367

Underwood AJ (1984) The vertical distribution and seasonal abundance of intertidal microalgae on a rocky shore in New South Wales. J Exp Mar Biol Ecol 78:199-220

Williams GA, Morritt D (1991) Patterns of foraging in Patella vulgata (L.). In: Myers A, Little C, Costello M, Partridge J (eds) The ecology of Lough Hyne. Royal Irish Academy, Dublin, p 61-69

Submitted: February 17, 2004; Accepted: May 17, 2004

Proofs received from author(s): September 6, 2004 